\title{
GÊNERO, VIOLÊNCIA E MORTE NO ROMANCEIRO DA INCONFIDÊNCIA
}

\author{
GENDER, VIOLENCE AND DEATH IN ROMANCEIRO DA \\ INCONFIDÊNCIA
}

\section{Sandra Sacramento ${ }^{2}$}

RESUMO: Analisa-se, no Romance IV ou Da Donzela Assassinada e no XI Romance XI ou Do Punhal e da Flor, constantes do Romanceiro da Inconfidência (2012), a identificação de voz do ator social no feminino, que esteve no cenário da derrama e que sofreu a violência paterna ou de parente próximo, em consequência da ambição desmedida pela posse de ouro e pedras preciosas, pois cada família disputa/privilégio mais antigos;/ e Por ódio, cobiça, inveja/ vai sendo o inferno traçado/ (MEIRELES, p.48-49), nas cercanias de Vila Rica, nas Minas Gerais do século XVIII; procurando estabelecer elos com a sociedade atual brasileira. Desta sorte, problematizase a coordenada: ontologia-epistemologia-ética-estética, que elegeu um determinado sujeito de conhecimento, na atribuição do certo/errado, justo/injusto e do belo/feio; com a negação da memória e vida plena à alteridade, sem levar em conta o rosto desejante do outro em suas demandas, assente ao privado.

Palavras-chave: Gênero. Violência. Cidadania. Feminicídio.

ABSTRACT: It is analyzed, in Romance IV or The Murdered Maiden and in Romance $\mathrm{XI}$ or The Dagger and Flor, contained in the Romanceiro da Inconfidencia (2012), the voice identification of the social actor in the feminine, who was in the scene of the spill and who suffered parental or close relatives violence, as a result of the excessive ambition for possession of gold and precious stones, because of each family disputes/oldest privilege; / and For hatred, greed, envy/hell is being traced / (MEIRELES, p. 48-49), in the surroundings of Vila Rica, in Minas Gerais of the XVIII century; seeking to establish links with the current Brazilian society. In this way, the coordinate is problematized: ontology-epistemology-ethics- aesthetics, which elected a certain subject of knowledge, in the attribution of right/wrong, fair/unfair and the beautiful/ugly; with the denial of memory and full life to the otherness, without taking into account to the desiring face of the other in his demands, based on the private.

Keywords: Gender. Violence. Citizenship. Feminicide.

\footnotetext{
${ }^{1}$ Artigo recebido em 14 de agosto de 2019 e aceito para publicação em 20 de novembro de 2019 . ${ }^{2}$ Com Pós-doutorado pela Université Poitiers-France; Professora plena na Universidade Estadual de Santa Cruz - Ilhéus, Bahia; E-mail: sandramsacra@uesc.br; Orcid: https://orcid.org/0000-0002$\underline{5533-7909}$ 


\section{Introduçầo}

Cecilia Meireles entende que a literatura fala do chamado real, enquanto constructo social e, para tanto, a fatura estética não se encontra distante das condições de produção do locus enunciativo, onde os personagens, vistos aqui como atores sociais, reivindicam sua representação, através do direito à fala, vinculados à tríade: conhecimento (epistemologia), juízo (ética para todos/as) e ação (pragmática), da psicologia social (JODELET, 2012). Esses personagens/atores sociais, como seres de fala, surgem como possibilidade de mudança, por empreenderem representações contrárias ao sujeito ontológico descontextualizado, habitante do mundo das essências transcendentais, do a priori, como via Kant da Crítica da Razão Pura (2001). Nesta ordem de ideias, conceitos como "realidade", "conhecimento" e "ser", vistos no passado na ordem teleológica do Ser-ser-objeto, passam a ser concebidos como processos sustentados em "verdades contextualizadas", em que o afetivo, o econômico, o gênero, a etnia ou outro ponto de ancoragem indentitário acabam intervindo na concepção do ser e do conhecer; na medida em que a relação entre o sujeito cognoscente e as circunstâncias, ocorre de forma sempre fantasmagórica, de uma presença na ausência (DERRIDA, 2008).

Então, as enunciações a serem vistas aqui, denunciam a violência e morte impostas a mulheres jovens, - filhas de homens, que enriqueceram, devido à exploração das minas e da mão de obra escrava utilizada - e vêm revestidas dos recursos retóricos, colocados em relação de força frente aos discursos correntes legitimados, em mandonismo e arbítrio de uma classe, em detrimento da valorização da alteridade, nas cercanias da Vila Rica do século XVIII. Desta sorte, refletem o pensamento da mulher escritora e colonizada, que não ousou escrever uma epopeia, mas sim optou pelo romance, popular e da gente pequena. Em uma Conferência proferida na Casa dos Contos em Ouro Preto, em 1955, afirma a escritora:

Muitas vezes me perguntei por que não teria existido um escritor do século XVIII - e houve tantos, em Minas! - que pudesse por escrito essa grandiosa e comovente história. No decorrer das minhas incertezas e dos meus escrúpulos em aproximar-me de tema tão grave, os fantasmas começaram a repetir suas próprias palavras de outrora (2012, p. 22-23). 
Por isso, delega voz àquelas em forma de fantasma, que gritam em busca de atendimento (2012), cuja ética se dá através da responsabilidade, diante da violência, em atenção ao rosto desejante do outro (LÉVINAS, 2016), alusivo a tempo/espaço dialógico do a posteriori, gerador de conhecimento, juízo e ação (JODELET, 2012), de auto representação engendrada pela psicologia social. Para Lévinas, de Le temps et l'autre (2016), o sentido da relação com o outro é originário e fundador de todas as outras relações com o ser. É essencial respeitar a alteridade do outro, de modo intersubjetivo, e não mais tentar absorvê-la pela identidade do mesmo; pois, em nome da ordem e da manutenção de privilégios, o transcendente universal ontológico da filosofia ocidental destituiu as circunstâncias concretas, que pudessem levar à dissidência. Também serão utilizadas obras de Judith Butler, que tratam da biopolítica, isto é, quando vê o corpo como arena política, na possibilidade de equalização entre a vivência individual e a moral, instituída na esfera pública, cuja ética, calcada no priori do mesmo, silenciou a alteridade e toda sorte de violência nela desferida; tal como ocorre nos dois romances eleitos para esta pesquisa. Entre outras, destacam-se: Problemas de gênero: feminismo e subversão da identidade (2008), Dar cuenta de sí mismo: violencia, ética y responsabilidad (2012) e ainda $Q u^{\prime}$ est-ce qu'une vie bonne? (2014).

Seguindo o raciocínio de que a obra de arte fala do mundo, a partir de um contexto de fala, as enunciações; no caso específico, no Romance IV ou Da Donzela Assassinada e no Romance XI ou Do Punhal e da Flor do Romanceiro da Inconfidência (2012) de Cecilia Meireles, encerram a narrativa em verso, popular, medieval e oral, de cunho épico lírico, - une epopée des petites gens - distante dos grandes feitos heroicos da nação, próprios da epopeia clássica, de cunho etno e falocêntrico. Tais enunciações encontramse revestidas de recursos retóricos e, desta sorte, refletem o pensamento da mulher escritora e daquela para quem empresta a voz em busca do eu atendido, na linha crítica do pós-feminismo com Judith Butler, e do rosto desejante do outro (LÉVINAS, 2016); em sintonia com contexto do locus enunciativo, alusivo a tempo/espaço dialógico-pragmático. Para Lévinas, a linguagem, enquanto estrutura formal, pode potencializar uma representação e rasurar o impulso totalizador da ordem do mesmo; sendo o sentido da relação com o outro, isto é, com a alteridade humana, originário e fundador de todas as outras relações com o ser. É essencial respeitar a 
alteridade do outro, de modo intersubjetivo, e não mais tentar absorvê-la pela identidade do mesmo.

\section{Pobres meninas ricas...}

Aderimos, assim, ao literário, como fatura estética datada, em circunstância, como constructo social, não distante das condições de produção do locus enunciativo; por isso, vinculada à tríade: conhecimento (epistemologia), juízo (ética para todos/as) e ação (pragmática) (JODELET, 2012); em atenção ao regime textual, com suas normas retóricas em figurativização metafórica e simbólica, como também ao contexto de referência, de modo proativo do sujeito da enunciação no feminino. Sem as amarras do essencialismo conceitual, a mulher, ao reivindicar seu poder de fala, insinua um possível empoderamento de direito, em apreensão suspeitosa, acerca do projeto emancipatório da modernidade, que, quase sempre, narrou o outro/a à luz de conveniências, que lhe eram estranhas.

Tal estrutura amparou a tradição ocidental, historicista e teleológica, cuja dinâmica legitimada pela Aufklärung da superação, fazia eco ao princípio de base dicotômica e excludente, em terras, que estivessem sob o domínio europeu. Com a negação de qualquer auto representação, na medida em que os habitantes locais não eram considerados humanos (ontologia), seus saberes não passavam pela razão (epistemologia), não detinham valores morais (ética) e suas produções culturais não poderiam ser incluídas no rol do cânone literário ocidental. Nesta coordenada, o chamado universal, impôs-se a partir de um particular etno-falocêntrico, sem possibilidade de lhe ser aplicado o princípio da contradição.

Por outro lado, as falas do Romanceiro da Inconfidência (2012), encenam um locus enunciativo, atinente ao Brasil, fazendo parte do Reino Unido de Portugal e Algarve; pois, no século XVIII, quando ocorreu a Inconfidência Mineira, ainda não éramos independentes de Portugal e, muito menos, adotávamos a República. Nossas instituições, à mercê das normas portuguesas, seguiam ordens à distância, reverberando a assimetria entre a Corte (=centro) e a Colônia (=periferia). Então, nesta relação de poder, como transitavam mulheres como aquelas que aparecem no Romance IV ou $D a$ 
Donzela Assassinada e o Romance XI ou Do Punhal e da Flor, a seguir reproduzidos ${ }^{3}$ :

Romance IV ou Da Donzela Assassinada

"Sacudia o meu lencinho/para estendê-lo a secar. /Foi pelo mês de dezembro, /pelo tempo do Natal. /Tão feliz que me sentia, /vendo as nuvenzinhas no ar, /vendo o sol e vendo as flores/nos arbustos do quintal, /tendo ao longe, na varanda, /um rosto para mirar!

"Ai de mim, que suspeitaram/que lhe estaria a acenar! /Sacudia o meu lencinho/para estendê-lo a secar. /Lencinho lavado em pranto, /grosso de sonho e de sal, /de noites que não dormira, /na minha alcova a pensar, /- porque o meu amor é pobre, /de condição desigual.

"Era no mês de dezembro/pelo tempo do Natal. /Tinha o amor na minha frente,

/tinha a morte por detrás:/desceu meu pai pela escada, /feriu-me com seu punhal. / Prostrou-me a seus pés, de bruços, /sem mais força para um ai! /Reclinei minha cabeça em bacia de coral. /Não vi mais as nuvenzinhas/que pasciam pelo ar./Ouvi minha mãe aos gritos e meu pai a soluçar, /entre escravos e vizinhos, /e não soube nada mais. /

"Se voasse o meu lencinho, /grosso de sonho e de sal, /e pousasse na varanda, /e começasse a contar/que morri por culpa do ouro/- que era de ouro esse punhal/que me enterrou pelas costas/a dura mão de meu pai -/sabe Deus se choraria/quem o pudesse escutar, /- se voasse o meu lencinho/e se pudesse falar, /como fala o periquito/e voa o pombo torcaz...

"Reclinei minha cabeça/em bacia de coral. /Já me esqueci do meu nome, /por mais que o queira lembrar! /"Foi pelo mês de dezembro, /pelo tempo do Natal. /Tudo tão longe, tão longe, /que não se pode encontrar. /

Mas eu vagueio sozinha, /pela sombra do quintal, /e penso em meu triste corpo, /que não posso levantar, /e procuro o meu lencinho, /que não sei por onde está, /e relembro uma varanda/que havia neste lugar.../

“Ai, minas de Vila Rica, /santa Virgem do Pilar! /Dizem que eram minas de ouro.../- para mim, de rosalgar,

\footnotetext{
${ }^{3}$ As aspas presentes nas citações fazem parte do poema.
} 
/para mim, donzela morta/pelo orgulho de meu pai. /(Ai, pobre mão de loucura,/que mataste por amar!) /Reparai nesta ferida/que me fez o seu punhal:/gume de ouro, punho de ouro, /ninguém o pode arrancar! /Há tanto tempo estou morta! /E continuo a penar."/ (p. 50-52).

Nota-se que a menina, ao narrar as circunstâncias de sua morte, faz menção à cena bastante contundente, pois é alvejada pelas costas e se volta, não para dialogar com o pai, mas sim para lhe cair aos pés, já morta. Pode-se notar que a menina, ao se comunicar com o namorado, está em conexão com a rua, com o espaço exterior, mas esse não lhe era permitido, mas, somente o privado, do doméstico, como era esperado para a mulher, pelo regime patriarcal. Ao narrar os fatos, encena uma proatividade, na emissão de juízo, que não ocorria, de fato, pois é ela quem narra em detalhe a sua morte, atribuindo ao ouro a causa de tal desgraça: /morri por culpa do ouro/. Ainda que se limite às características materiais ao instrumento utilizado pelo pai: /que era de ouro esse punhal/, nota-se que o motivo é bem outro, isto é, a arrogância advinda da posse do metal; como se confirma em versos da estrofe seguinte: /pelo orgulho de meu pai. / O verso da mesma estrofe: / (Ai, pobre mão de loucura, /que mataste por amar!) / é bastante emblemático, pois se utiliza de expressão ainda hoje corrente na justificativa da morte da mulher, pelo marido, por amar. No caso em questão, é a morte de uma filha jovem por um pai, possesso, por ser o pretendente de classe social inferior à da moça. Seja lá por que motivo for, os instrumentos legais hoje já especificam crimes como este, tipificado com feminicídio, com a previsão de prisão e condenação de seus autores. Os índices de feminicídios chegaram no Brasil, em 2018, a 68.000 casos. $^{4}$

As violências praticadas contra as mulheres devido ao seu sexo assumem múltiplas formas. Elas englobam todos os atos que, por meio de ameaça, coação ou força, Ihes infligem, na vida privada ou pública, sofrimentos físicos, sexuais ou psicológicos com a finalidade de intimidá-las, puni-las, humilhá-las, atingilas na sua integridade física e na sua subjetividade (ALEMANY, 2009, p. 271).

${ }^{4}$ https://www.redebrasilatual.com.br/cidadania/2019/03/estudo-revela-68-mil-casos-de-violenciacontra- a-mulher-noticiados-em-2018 
Tais cifras insistem em se manterem devido, talvez, a um leque de fatores. Primeiro a certeza da impunidade, segundo à falta de políticas públicas efetivas, que promovam a igualdade de gênero, na sociedade, em relação a emprego e renda; e terceiro, em grande medida, à falta de sororidade entre mulheres, que sempre foram vistas com seres fúteis em competição. No editorial do jornal Le Monde, com título, Les féminicides, un combat de société, consta: Desde 2016, os relatórios da ONU enfatizam que é "a forma mais extrema de violência contra as mulheres e a maior manifestação de desigualdade de gênero" ${ }^{5}$.

Em relação ao poema, aqui analisado, notamos que a mãe da jovem morta pelo pai, não se coloca, no sentido de incriminá-lo, pois ambos têm praticamente a mesma reação: /Ouvi minha mãe aos gritos e meu pai a soluçar, /entre escravos e vizinhos/. A mãe tem uma reação pontual à agressão e, provavelmente, após a cerimônia fúnebre da filha, voltou para os seus afazeres, pois, não contando com o amparo legal, que pudesse punir o pai assassino, não alterou seu curso de vida, refugiando-se na religião, como espaço da resignação.

No Romance XI ou Do Punhal e da Flor, a questão que chama atenção, logo de início, é a fraternidade, entre iguais.

\begin{abstract}
Rezando estava a donzela, /rezando diante do altar. /E como a viam mirada/pelo Ouvidor Bacelar! /Foi pela Semana Santa/. Muito se esquecem os homens, /quando se encantam de amor. /Mirava em sonho, a donzela, /o enamorado Ouvidor. /E em linguagem de amoroso/arremessou-Ihe uma flor. /
\end{abstract}

Caiu-Ihe a rosa no colo. /Girou malícia pelo ar./Vem, raivoso, Felisberto, seu parente, protestar. /Era na Semana Santa. /E estavam diante do altar. / Mui formosa era a donzela, /E mui formosa era a flor. /Mas sempre vai desventura onde formosura for. /

Vede que punhal rebrilha/na mão do Contratador! /Sobe pela rua a tropa/que já se mandou chamar. /E era à saída da igreja, /depois do ofício acabar. /Vede a mão que há pouco esteve/contrita, diante do altar! /

Num botão resvala o ferro:/e assim se salva o Ouvidor. /Todo o Tejuco murmura, /- uns por ódio, uns por

${ }^{5}$ Acesso em 06 de julho de 2019. Tradução nossa. 
amor. /Subir um punhal nos ares, /por ter descido uma flor! / (p. 61-62).

No romance acima reproduzido, se repete o apego à posse, tanto pelo ouro, quanto pela mulher, no caso em questão, uma moça jovem solteira, que supostamente, respondeu ao flerte do Ouvidor Bacelar, em agradecimento à flor arremessada por esse.

Logo, um parente, de nome Felisberto, autorizado por narrativas dominantes de que mulher não sabe se defender e precisa sempre de um homem próximo, que assim o faça; e, logo avisa o Contratador do fato, que chega na tentativa de matar o Ouvidor: Vede que punhal rebrilha/na mão do Contratador! / Mas, por um golpe de sorte: Num botão resvala o ferro:/e assim se salva o Ouvidor.

Essas meninas, constantes dos dois romances, aqui analisados, enfrentavam toda sorte de arbitrariedade, podendo ser comparadas aos escravos, seus contemporâneos, que tudo padeciam e nada obtinham. Os homens de negócio do local enriqueceram e fundaram uma espécie de casta, na qual só transitavam os autorizados pelo sistema, cuja fraternidade entre iguais impunha-se em uma rede de concessão e arbítrio, como aparece no Romance XI ou Do Punhal e da Flor. A fatria formada pelo sistema patriarcal impõe-se, enquanto grupo viril, que defende antropologicamente seus territórios e valores, com o uso, quase sempre da violência, sendo a covardia, mesmo entre opositores, difícil de ser assumida. Seus membros podem ser antagônicos economicamente, por isso, conspiram entre si, com perseguições e julgamentos; tal como ocorria no entrono da Vila Rica do século XVIII. Daí seus níveis, sendo universal apenas aceitação das regras vigentes (VALCARCEL, 2012).

Graças ao enriquecimento rápido, o Contratador é imbuído do poder de vida e morte, daquele/a com quem lidava. Esse dispunha da autorização para negociar com ouro e pedras preciosas e encontrou facilidade na mobilidade social, formando com seus pares, uma classe de nouveau riche, sem tradição, mas com forte apego ao status alcançado. Por outro lado, o Ouvidor, cargo oriundo do regime absolutista despótico esclarecido, já influenciado pela razão iluminista, tinha por função ouvir os problemas enfrentados pela população, mas não possuía bens, se comparados aos dos Contratadores. 
Neste sentido, dá-se credito ao que defende Jacques Derrida de Gramatologia, ao problematizar a questão do significado transcendental (DERRIDA, 2008), como visto pela tradição ocidental. Nesta ordem de ideias, identificamos Romance IV ou Da Donzela Assassinada e o Romance XI ou Do Punhal e da Flor relações de gênero e classe em bases hierárquicas, cujo eixo estruturado determinou a representação do humano (ontologia), da razão (epistemologia), do justo (moral) e do belo (estética). Aliás, no Romance LIII ou Das Palavras Aéreas, a poeta problematiza estas questões, quando evidencia que a palavra, em circunstância, pragmático-discursiva, é que se encontra envolvida na atribuição da Verdade. Vejamos o excerto:

Ai, palavras, ai, palavras, /que estranha potência, a vossa! / Todo o sentido da vida/principia à vossa porta;/o mel do amor cristaliza/seu perfume em vossa rosa;/sois o sonho e sois a audácia, / calúnia, fúria, derrota.../

Entende-se, desta sorte, que o ato de nomear padece de uma espécie de incompletude precária, atado somente por cabos imaginários de sustentação. E, qualquer alteração no conceito de Verdade, insidiosamente, impositiva e autoexplicativa, só poderá advir pelas ações afirmativas, rumo ao estado de direito, da paridade, do empoderamento, em relações simétricas, em síntese, pela universalização dos Direitos Humanos. Como afirma Amélia Valcarcel em Feminismo en el mundo global:

Somente uma democracia participativa assegura o exercício das liberdades e o gozo dos direitos adquiridos. Por mais imperfeita que ela seja, é sempre melhor que uma ditadura de qualquer tipo, social, religiosa, carismática (VALCARCEL, 2012, p. 324, tradução minha).

Então, o regime democrático requer para o seu aperfeiçoamento, a ausculta constante em variadas instâncias, individual ou em associação. Somente assim, a Declaração Universal dos Direitos Humanos, de 1948, com a complementação da Carta das Nações Unidas e da Convenção sobre a Eliminação de Todas as Formas de Discriminação contra as Mulheres (CEDAW/ONU), de 1979, não se tornam vazias, na execução de seus objetivos, no que diz respeito ao aumento da capacidade de cidadania, como forma de pôr em prática os direitos individuais almejados, visando, em síntese, ao bem- 
estar. Há de se ressaltar o ano de 1975, como o Ano Internacional das Mulheres, marco emblemático da ONU, no reconhecimento do feminismo e na inclusão dos problemas atinentes às mulheres nas pautas de governos signatários, como o Brasil. E a mulher, oriunda de países não-centrais, que foram colonizados, requer, através da diversidade que experimenta, a possibilidade da instauração de uma espécie de rasura ao modelo posto pela colonização, seja por seu gênero, etnia ou classe social, em constante tradução híbrida em seu modo de vida.

No caso do Brasil de hoje, devem ser levadas em conta leis, como a Lei Maria da Penha de 2006, que cria mecanismos para coibir a violência doméstica e familiar, nos termos do $\S 8$ do art. 226 da Constituição Federal, da Convenção sobre a Eliminação de Todas as Formas de Discriminação conta as Mulheres e da Convenção Interamericana para Prevenir, Punir e Erradicar a Violência contra a Mulher; dispõe sobre a criação dos Juizados de Violência Doméstica e Familiar contra a Mulher, altera o Código de Processo Penal, o Código Penal e a Lei de Execução Penal e dá outras providências (BRASIL, 2006); além da Lei do Feminicídio, isto é, a Lei 13.104/2015, que modificou o código penal e qualificou o feminicídio como crime hediondo no Brasil. Tal crime é praticado contra mulheres em razão da condição de ser do sexo feminino (BRASIL, 2015). Então, se o gênero é construção, podemos pensá-lo em uma nova ordem que não a binária, maniqueísta, heterossexual e hierárquica, produto de "ficções reguladoras do sexo e do gênero" (BUTLER, 2008, p. 68).

Judith Butler, em Problemas do gênero: feminismo e subversão da identidade (2008), ao ver o gênero como representação social, defende a teoria de que todo processo simbólico narrativo vem a ser uma violência instituída, instando no indivíduo a necessidade de mediação, através de processo cognitivo, que passa necessariamente, pela vontade, para que esse possa se inserir em uma rede identitária de pertencimento; por isso, a tríade sexo-gênero-desejo, manteve-se na tradição ocidental, através de mecanismos construtivistas em reiteração pragmática. E, legitimando seu posicionamento, afirma que:

Como ponto de partida de uma teoria social do gênero, a concepção universal da pessoa é deslocada pelas posições históricas ou antropológicas que compreendem o gênero como uma relação entre 
sujeitos socialmente construídos, em contextos específicos. Este ponto de vista relacional ou contextual sugere que o que a pessoa "é" - e a rigor, o que o gênero "é" - refere-se sempre às relações construídas em que ela é determinada (BUTLER, 2008, p. 29).

Judith Butler, por outro lado, em Dar cuenta de sí mismo: Violencia ética y responsabilidade (2012), exorta a adoção de uma ética do cuidado para entender os limites do que pode ser dito e feito, que condicionam todos e cada um dos atos individuais. Em se adotando respeito, alcança-se uma tomada de postura crítica diante do mundo. Diz ela que é preciso recostruir as regras, que estabelecem a impossibilidade de sujeito, a partir da irrupção na dimensão social das normas. Desta sorte, engendra a possibilidade de tessitura de uma auto representação, assente à deontologia, isto é, envolvida na demanda das necessidades e fins, a partir do que acontece individualmente, em respeito ao rosto desejante, através da biopolítica, pois a vida, o corpo, por si só, merecem respeito e ensejam uma política, que pense a mulher, não de modo essencialista, mas como um ser de demandas.

\section{Conclusằo}

Portanto, tivemos por objetivo neste artigo analisar no Romance IV ou Da Donzela Assassinada e no XI Romance XI ou Do Punhal e da Flor, constantes do Romanceiro da Inconfidência (2012), a identificação de voz do ator social no feminino, que esteve no cenário da derrama e que sofreu a violência de morte ou mesmo de domínio desenfreado, atitudes paternas ou de parente próximo, em consequência da ambição desmedida pela posse de ouro e pedras preciosas, pois cada família disputa/privilégio mais antigos;/ e Por ódio, cobiça, inveja/ vai sendo o inferno traçado/ (MEIRELES, p. 48-49), nas cercanias de Vila Rica, nas Minas Gerais do século XVIII.

Foram estabelecidos elos com a sociedade atual brasileira, cuja ocorrência de feminicídio alcança índices inimagináveis, como atestamos aqui, em detrimento do respeito aos Direitos Humanos das mulheres e do seu pleno acesso à cidadania.

Desta sorte, foi problematizada a coordenada: ontologiaepistemologia-ética- estética, que elegeu um determinado sujeito de conhecimento, na atribuição do certo/errado, justo/injusto e do belo/feio; com a negação da memória e vida plena à alteridade, sem levar em conta o 
rosto desejante do outro em suas demandas, assente ao privado. Contamos com teorias (LÉVINAS, 2016); (BUTLER, 2008, 2012, 2014); (JODELET, 2012), entre outras, que almejam à possibilidade de equalização entre o que acontece individualmente, que se possa expandir para o coletivo, e a moral, instituída na esfera pública, cuja ética, calcada no priori do mesmo, vai muito além dos interesses da alteridade.

\section{Referências}

ALEMANY, C. Violências. Tradução: Naira Pinheiro. In: Dicionário Crítico do Feminismo. Org. Helena Hidrata. Françoise Laborie. Hélène Le Doaré. Danièle SenoTier. São Paulo: Editora UNESP, 2009. p. 271-276. Disponível em: <https://www.redebrasilatual.com.br/cidadania/2019/03/estudo-revela-68mil-casos-de- violencia-contra-a-mulher-noticiados-em-2018>. Acesso em 3 de agosto de 2019.

BRASIL. Lei n.11.340, de 7 de agosto de 2006. Lei Maria da Penha. Cria Mecanismos para coibir a violência doméstica e familiar contra a mulher. Disponível em: <http://www.presidencia.gov.br >. Acesso em 27 de maio de 2019.

BRASIL. Lei n.13.104, de 9 de março de 2015, conhecida como a Lei do Feminicídio. A lei altera o Código Penal (art.121 do Decreto Lei n.2.848/40), incluindo o feminicídio como uma modalidade de homicídio qualificado, quando crime for praticado contra a mulher por razões da condição de sexo feminino, entrando no rol dos crimes hediondos. Disponível em: <http://www.presidencia.gov.br>. Acesso em 27 de maio de 2019.

BUTLER, J. Qu' est-ce qu'une vie bonne? Traduit de l' anglais et préfacé par Martin Rueff. Paris: Payot, 2014.

BUTLER, J. Dar cuenta de sí mismo: Violencia, ética y responsabilidad. Buenos Aires: Amorrortu, 2012.

BUTLER, J. Problemas de gênero: Feminismo e subversão da identidade. Tradução de Renato Aguiar. Rio de Janeiro: Civilização Brasileira, 2008.

DERRIDA, J. Gramatologia. Tradução de Miriam Schnaiderman e Renato Janine Ribeiro. São Paulo: Perspectiva, 2008.

JODELET, D. et al. Les représentations sociales. Paris. PUF, 2012.

LE MONDE. Les féminicides, un combat de société. Le Monde, Paris, 06 jul. 2019.

<https://www.lemonde.fr/idees/article/2019/07/06/les-feminicides-uncombat-de-societe 5486229 3232.html>. Acesso em 06 de julho de 2019. 
LÉVINAS, E. Le temps et l'autre. Paris: PUF, 2016.

KANT, I. Crítica da razão pura. Tradução de Manuela Pinto dos Santos. Lisboa: Fundação Calustre Gulbenkian, 2001.

MEIRELES, C. Romanceiro da Inconfidência. Organização e apresentação de Ana Maria Lisboa de Mello. Porto Alegre: L\&PM, 2012.

VALCÁRCEL, A. Feminismo en el mundo global. Cátedra: Madrid, 2012. 